\title{
Bromine-lithium exchange: An efficient tool in the modular construction of biaryl ligands
}

\author{
Laurence Bonnafoux, Frédéric R. Leroux ${ }^{*}$ and Françoise Colobert ${ }^{*}$
}

\section{Full Research Paper}

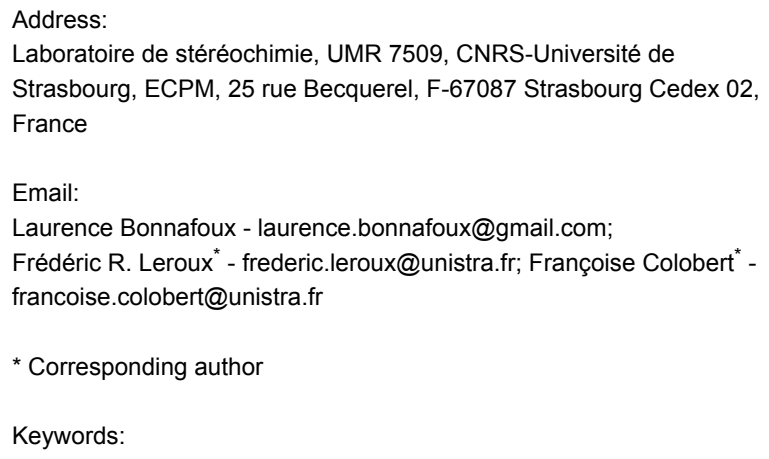

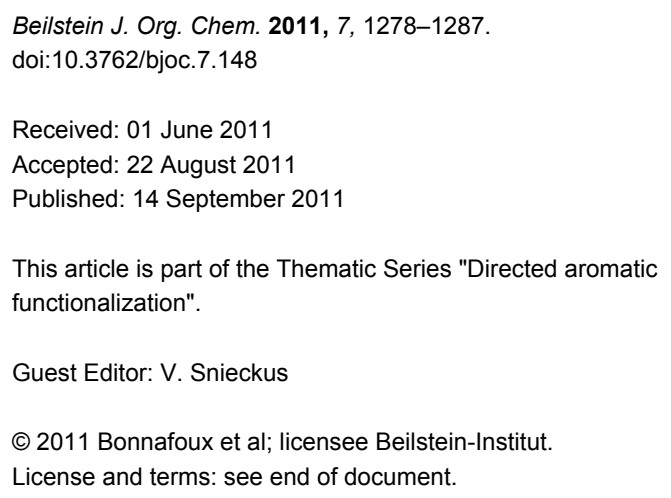

\begin{abstract}
Regioselective bromine-lithium exchange reactions on polybrominated biaryls enable the modular synthesis of various polysubstituted biphenyls such as bis(dialkylphosphino)-, bis(diarylphosphino)- and dialkyl(diaryl)phosphinobiphenyls. All permutations of substituents at the ortho positions of the biphenyls are possible. In a similar manner, one can gain access to monophosphine analogues. So far, such a process, based on the effective discrimination between bromine atoms as a function of their chemical environment, has been observed only sporadically.
\end{abstract}

\section{Introduction}

Atropisomeric biaryls are important compounds in various fields. In particular, pharmaceuticals and agrochemicals with biaryl substructures are of general interest [1]. In addition, they have widespread applications as ligands in catalysis, or in materials sciences [2]. The atropisomeric $C_{2}$-symmetric binaphthyl- or biphenyl-bridged diphosphine ligands BINAP [3], H8-BINAP [4], BIPHEMP [5], MeO-BIPHEP [6], SEGPHOS [7-9], P-Phos [10], SYNPHOS [11,12], $\mathrm{C}_{n}$-TUNAPHOS [13] and DIFLUORPHOS [14-16] and their analogues are well known as highly efficient chiral ligands for a variety of transition metal-catalyzed asymmetric transformations. The biphenyl backbone has the advantage that substituents at the 6- and 6'-positions can affect the dihedral angle of the biphenyl backbone, one of the key factors for ligand efficiency. Both the aryl phosphorus substituents and the biphenyl backbone can be tailored in order to modify the stereoelectronic profile of a ligand.

Most frequently, biaryls are prepared through transition metalcatalyzed reactions of suitable functionalized starting materials [17-22]. Although these methods are well established, alternatives are investigated in order to avoid expensive transition metals or ligands, which are especially required for the coupling of deactivated or sterically hindered substrates. 
Our group is developing new methods towards the synthesis of highly functionalized atropisomeric biphenyls [23-32]. We seek to perform their synthesis (a) in a modular way starting from a few common and easily available precursors; (b) with a high degree of structural diversity; (c) in a straightforward, short, reproducible manner; (d) in high yield and on multigram scale; and, last but not least, (e) with a restricted use of transition metals and ligands.

Polar organometallic chemistry [33-35] allows the performance of highly selective reactions. Therefore, it seemed to us the ideal tool to reaching this goal. In this context, we recently developed a novel transition metal-free aryl-aryl coupling protocol, the "ARYNE-coupling", which allows the preparation of di-, tri-, and even tetra-substituted ortho,ortho'-dibromobiphenyls [25,28,31,36-38]. These have the advantage that, by means of successive or simultaneous bromine-lithium exchanges, a huge panel of substituents can be introduced into the biphenyl backbone.

The bromine-lithium exchange reaction is certainly one of the most fundamental synthetic transformations [39]. Although this reaction was reported by C. S. Marvel in 1927 [40], G. Wittig [41] and H. Gilman [42-44] were the first to apply it in organic synthesis in the late thirties. Since then, this reaction has been considered as a mature method lacking both appeal and surprise [33], and only new applications of this reaction or mechanistic studies have been reported [30,32,33,45-55]. However, in the last few years, the halogen-metal permutation has recaptured its former role as one of the most important and versatile methods in organic synthesis. New exchange reagents, such as isopropylmagnesium chloride, its $\mathrm{LiCl}$ complex [53-61] and lithium tributylmagnesate $[62,63]$, have been developed and allow reactions under noncryogenic conditions [64-66]. New access routes to synthetically challenging aryl halide precursors have been devised.

A. Alexakis et al. recently achieved a significant breakthrough. They succeeded in the desymmetrization of prochiral polybrominated $[32,51]$ compounds by an asymmetric bromine-lithium exchange in the presence of a stoichiometric amount of chiral diamines. An enantiomeric excess of up to $63 \%$ was obtained [67]. H. Kagan et al. reported the desymmetrization of prochiral aromatic or vinylic dihalide substrates by halogen-metal exchange in the presence of a stoichiometric amount of diamines, with enantiomeric excess up to $26 \%$ [68]. Very recently, the Alexakis group achieved the catalytic bromine-lithium exchange allowing the preparation of biarylatropisomers in quantitative yields and enantiomeric excesses up to $82 \%[69]$.

Herein, we report on the preparation of $C_{1}$ analogues of the most efficient and popular $C_{2}$-symmetric biphenyl ligands. We will show that by means of regioselective bromine-lithium exchanges all possible permutations of bis(diaryldiphosphino)-, bis(dialkylphosphino)- and dialkyl(diaryl)phosphinobiphenyls become feasible. In a similar way, biphenyl-based monophosphine ligands were also obtained (Figure 1).

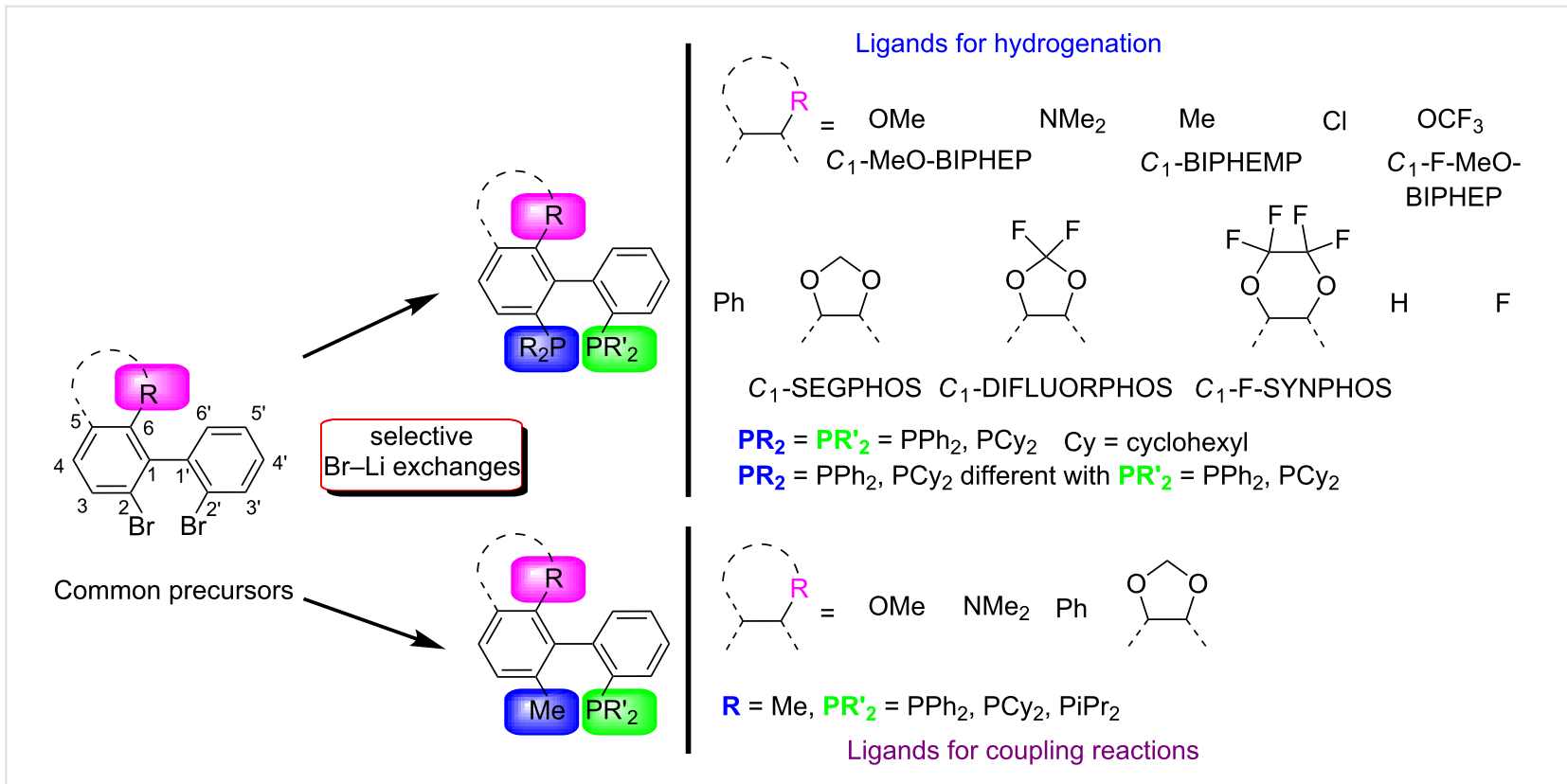

Figure 1: Modular synthesis of bis(diarylphosphino)-, bis(dialkylphosphino)- and dialkyl(diaryl)phosphinobiphenyls as well as monophosphinobiphenyls by means of polar organometallic chemistry. 


\section{Results and Discussion}

\section{Regioselective bromine-lithium exchange on polybrominated biphenyls}

Our group recently reported the efficient coupling of organolithium intermediates with arynes, the so-called "ARYNE coupling" $[25,31,36]$. This protocol is based on the formation of a thermodynamically stable aryllithium intermediate and its subsequent reaction with a 1,2-dibromobenzene derivative. The transient benzyne adds the aryllithium derivative, followed by in situ transfer of bromine between the resulting 2-biaryllithium intermediate and another molecule of 1,2-dibromobenzene. Mono-, di- or even tetra-substituted ortho-bromobiaryls can be obtained on a gram scale (Figure 2).

The intriguing question is whether one bromine would be exchanged preferentially on the substrate when the bromine atoms are not activated by adjacent heteroatoms. An effective discrimination between two bromine atoms as a function of their chemical environment has so far been observed only sporadically in such processes $[30,34,35,51,52,70-72]$.

Fortunately, the reaction occurred exclusively on the doubly halogenated ring when 2,2',6-tribromobiphenyl [28,38], obtained almost quantitatively by the ARYNE coupling protocol, was submitted to the bromine-lithium exchange reaction. When 2,2',6-tribromobiphenyl (1a) [28] was treated at $-78^{\circ} \mathrm{C}$ with $\mathrm{BuLi}$ and the intermediate aryllithium trapped with iodomethane, 2,2'-dibromo-6-methylbiphenyl (1b) was obtained in an excellent yield of $96 \%$. Analogously, when benzenesulfonylazide was used as an electrophile, 2-azido-2',6-dibromobiphenyl was obtained. The use of lithium aluminium hydride in ether at reflux for $4.5 \mathrm{~h}$ gave exclusively 2 -amino-2',6-dibromobiphenyl, which was submitted to a reductive methylation by means of formaldehyde and sodium cyanoborohydride. 2- $N, N$ Dimethylamino-2',6-dibromobiphenyl (1c) was obtained in an overall yield of $79 \%$ in 3 steps (Scheme 1). To introduce the methoxy group, 2,2',6-tribromobiphenyl (1a) was successively subjected to lithiation, borylation with fluorodimethoxyborane-diethyl ether, followed by oxidation with hydrogen peroxide and $O$-methylation with iodomethane in acetone. 2,2'-Dibromo-6-methoxybiphenyl (1d) was finally obtained in a very good global yield of $68 \%$ in 3 steps. Finally, we proposed to introduce the phenyl ring (1f, 95\%) by a regioselective Suzuki-Miyaura coupling via the iodo derivative 1e, the latter being obtained in $83 \%$ yield after trapping with iodine.

Similarly, as shown for 2,2',6-tribromobiphenyl (1a), when 6-substituted 2,2'-dibromobiphenyls $\mathbf{1} \mathbf{b}$-e were treated with just one equivalent of butyllithium in tetrahydrofuran at $-78{ }^{\circ} \mathrm{C}$, another regioselective bromine-lithium exchange occurs on the functionalized ring (Scheme 2). Trapping with iodomethane afforded the biphenyls 2 in high yield and perfect regioselectivity, except for $\mathrm{R}=\mathrm{Ph}$ (1f) and the benzodioxole derivative (1i), where the regioselectivity was slightly lower (91:9 and 92:8, respectively).

M. Schlosser and J. Gorecka-Kobylinska recently reported on the relative basicities of aryllithiums bearing methoxy, chlorine, fluorine, trifluoromethyl and trifluoromethoxy substituents at the ortho, meta, and para positions. Equilibration studies of two aryllithiums of comparable basicity with the corresponding bromo- or iodoarenes allowed them to determine the "basicity" (protodelithiation) increments $\Delta \Delta G$, derived from the equilibrium constants. The authors showed that the basicity increments are linearly correlated with the relative protonation enthalpies of the corresponding aryl anions in the gas phase. Compared with "naked" aryl anions, the basicity of aryllithiums mirrors the effects of ortho, meta, and para substituents to the extent of $36 \%, 30 \%$, and $25 \%$, respectively [73].

These results explain the difference in regioselectivity of the bromine-lithium exchange, between a bromine atom residing

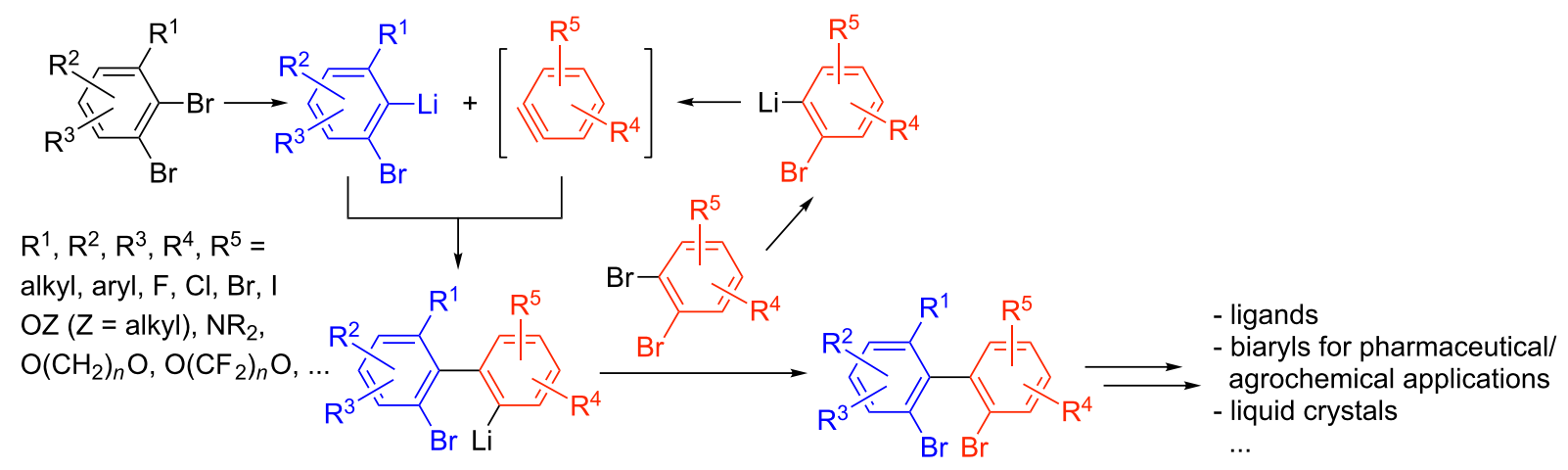

Figure 2: ARYNE coupling 


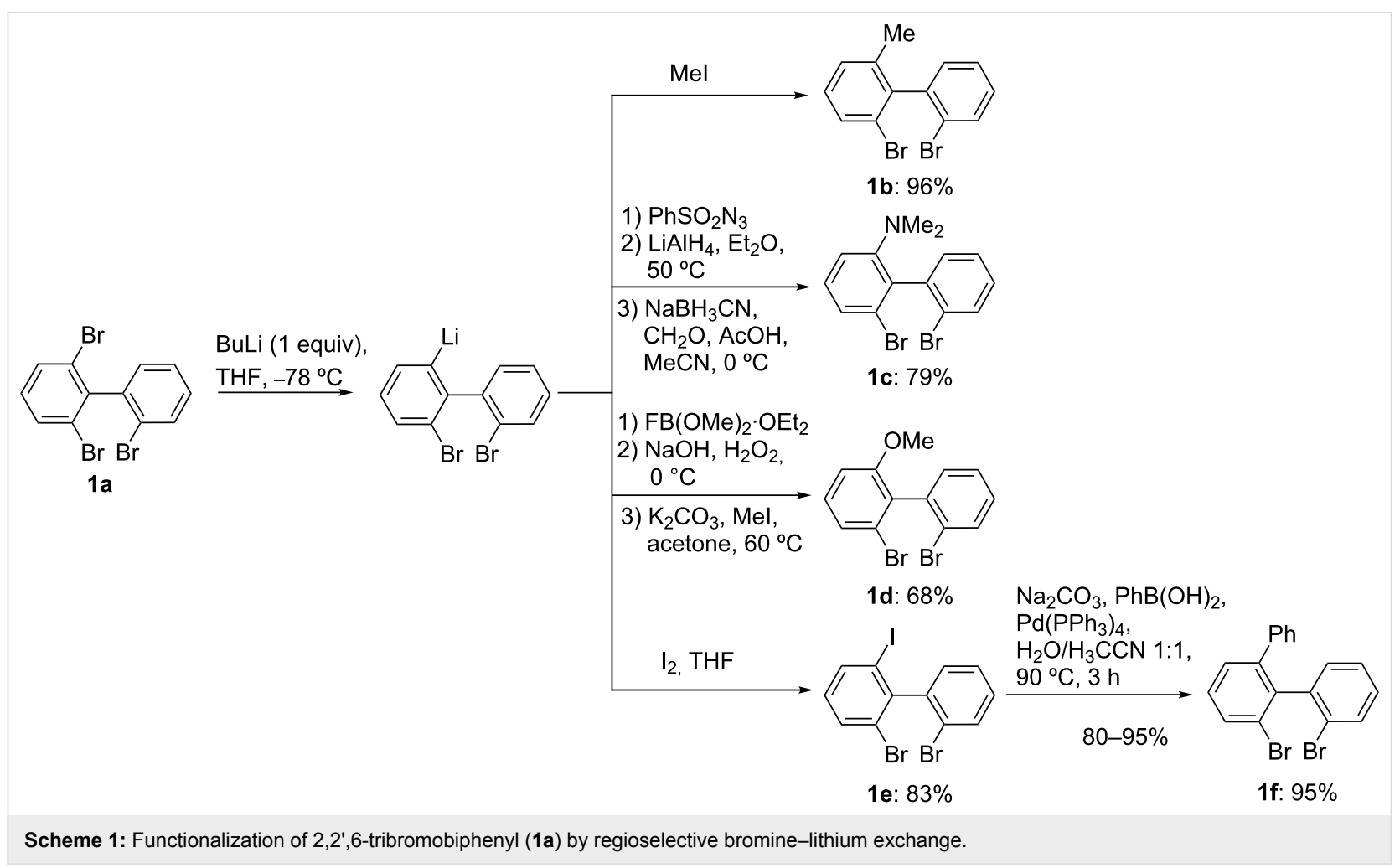

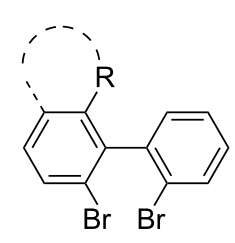
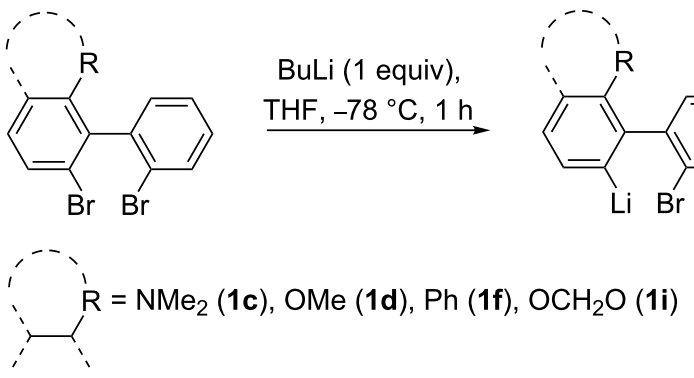
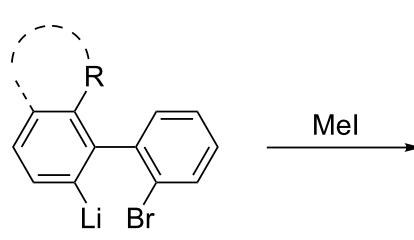

$$
\begin{aligned}
& \mathrm{NMe}_{2}(2 \mathbf{a}) \\
& \mathrm{OMe}(2 \mathbf{b}) \\
& \mathrm{Ph}(2 \mathrm{c}) \\
& \mathrm{OCH}_{2} \mathrm{O}(2 \mathrm{~d})
\end{aligned}
$$<smiles>[R]c1c(C)ccc(C)c1-c1ccccc1Br</smiles><smiles>[R]c1c(I)ccc(Br)c1-c1ccccc1C</smiles>

$\begin{array}{rr}\mathbf{8 1} \% & >99: 1 \\ \mathbf{7 4 \%} & >99: 1 \\ \mathbf{9 3} \% & 91: 9 \\ \mathbf{9 5 \%} & 92: 8\end{array}$

Scheme 2: Functionalization of 2,2'-dibromobiphenyls (1b-e) by regioselective bromine-lithium exchange.

on a phenyl ring that bears a "stabilizing" substituent at a remote meta position and a bromine atom on an "unstabilized" phenyl ring.

\section{Biaryl mono- and diphosphines}

In the following section we will show how a large family of biaryl mono- and diphosphines becomes readily accessible through these common building-blocks. The general access is depicted in Figure 3.

\section{Biarylmonophosphines: Path A}

From the methylated intermediates $\mathbf{2 a - d}$, new monophosphines became accessible in one additional step (Scheme 3). The bromine-lithium exchange was either performed with just one equivalent of butyllithium in tetrahydrofuran at $-78{ }^{\circ} \mathrm{C}$ (conditions $a$ ) or in toluene at $0{ }^{\circ} \mathrm{C}$ (conditions $b$ ). After cooling to $-78^{\circ} \mathrm{C}$, the lithiated intermediate was then allowed to react with a solution of $\mathrm{ClPCy}_{2}$, or $\mathrm{ClPPh}_{2}$ in toluene. In these cases, the monophosphines 3 were obtained in good yields (Scheme 3).

Single crystal X-ray analyses [74] of one ligand of each family $\left(\mathrm{R}^{1}=\mathrm{NMe}_{2}\right.$ (3a, Figure 4), OMe (3b, see Supporting Information File 3), $\mathrm{Ph}$ (3d, see Supporting Information File 4), $\mathrm{OCH}_{2} \mathrm{O}$ (3f, see Supporting Information File 5)) were performed in order to confirm their structure. Thus, we confirmed the selectivity of the different halogen-metal exchange reactions performed throughout the synthesis. 


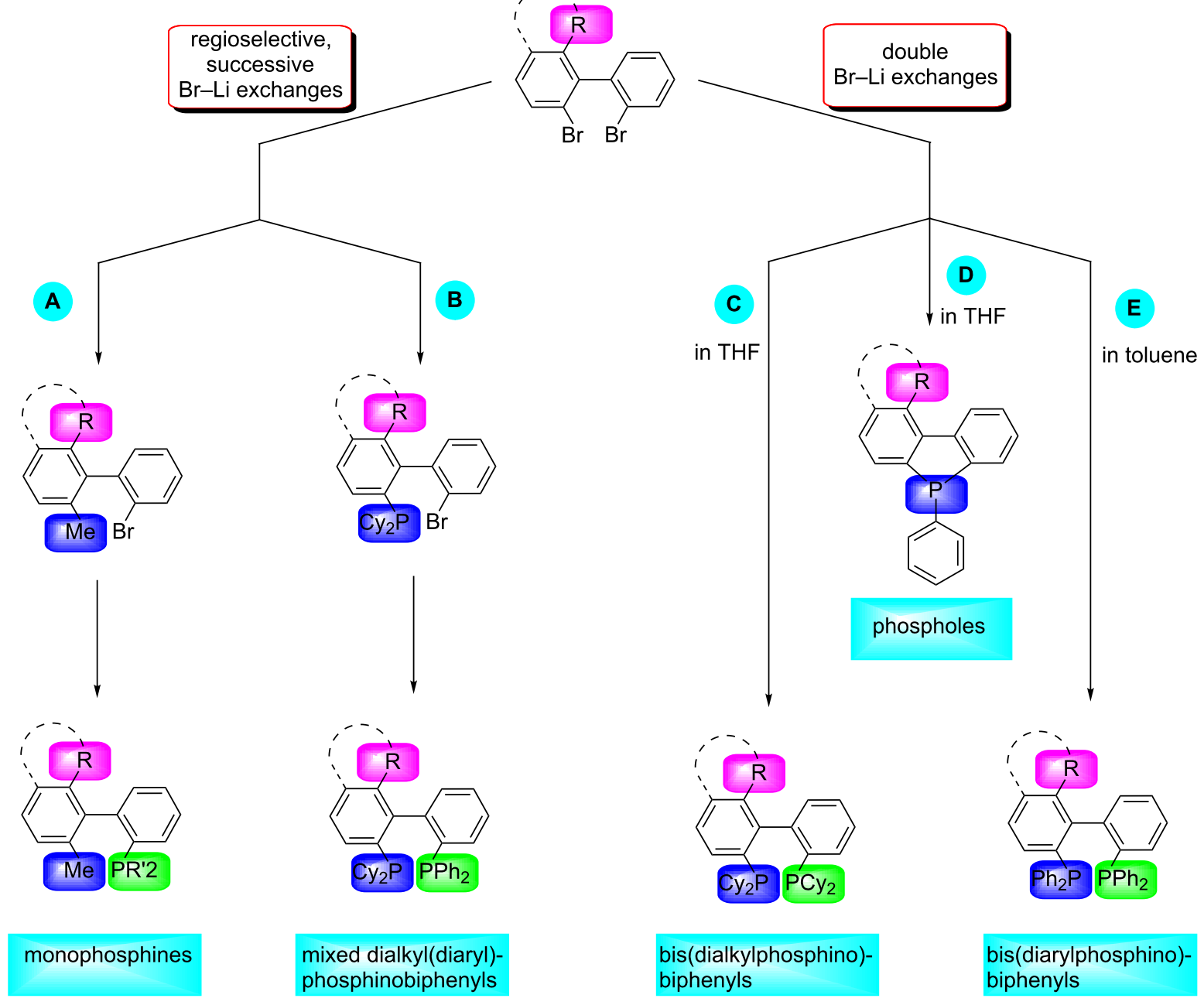

Figure 3: General access to biaryl mono- and diphosphine ligands; (Cy = cyclohexyl).

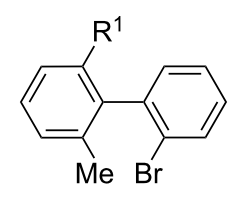

$\mathrm{R}^{1}=\mathrm{NMe}_{2}(\mathbf{2} \mathbf{a}), \mathrm{OMe}(\mathbf{2} \mathbf{b})$,

$\mathrm{Ph}(\mathbf{2 c}), \mathrm{OCH}_{2} \mathrm{O}(2 \mathrm{~d})$
1) conditions a: BuLi ( 1 equiv), THF, $-78^{\circ} \mathrm{C}, 1 \mathrm{~h}$ conditions $b$ : BuLi ( 1 equiv), toluene, $0^{\circ} \mathrm{C}, 15 \mathrm{~min}$

2) $\mathrm{CIPR}_{2}^{2}$, toluene, $-78^{\circ} \mathrm{C}, 1 \mathrm{~h}$

$\mathrm{R}^{1}=\mathrm{NMe}_{2}, \mathrm{PR}^{2}{ }_{2}=\mathrm{PCy}_{2}(\mathbf{3 a}): 66 \%$

$\mathrm{OMe}, \mathrm{PR}^{2}{ }_{2}=\mathrm{PPh}_{2}(\mathbf{3 b}): 68 \%$

$\mathrm{OMe}, \mathrm{PR}^{2}{ }_{2}=\mathrm{PCy}_{2}(\mathbf{3 c}): 76 \%$

$\mathrm{Ph}, \mathrm{PR}_{2}{ }_{2}=\mathrm{PPh}_{2}(\mathbf{3 d}): 65 \%$

$\mathrm{Ph}, \mathrm{PR}^{2}{ }_{2}=\mathrm{PCy}_{2}(3 \mathrm{e}): 66 \%$

$\mathrm{OCH}_{2} \mathrm{O}, \mathrm{PR}_{2}{ }_{2}=\mathrm{PCy}_{2}(3 \mathrm{f}): 63 \%$

Scheme 3: Synthesis of monophosphines 3; (Cy = cyclohexyl).

\section{Mixed dialkyl(diaryl)phosphinobiphenyls:}

\section{Path B}

In order to synthesize mixed diphosphines, we took advantage of the non-equivalence of the two phenyl rings towards lithia- tion. We started from the same dibromobiaryls $\mathbf{1}$ as before, but submitted them now to just one equivalent of butyllithium in THF. The aryllithium intermediate was then trapped with one equivalent of $\mathrm{ClPCy}_{2}$. The resulting monophosphine 4 was 


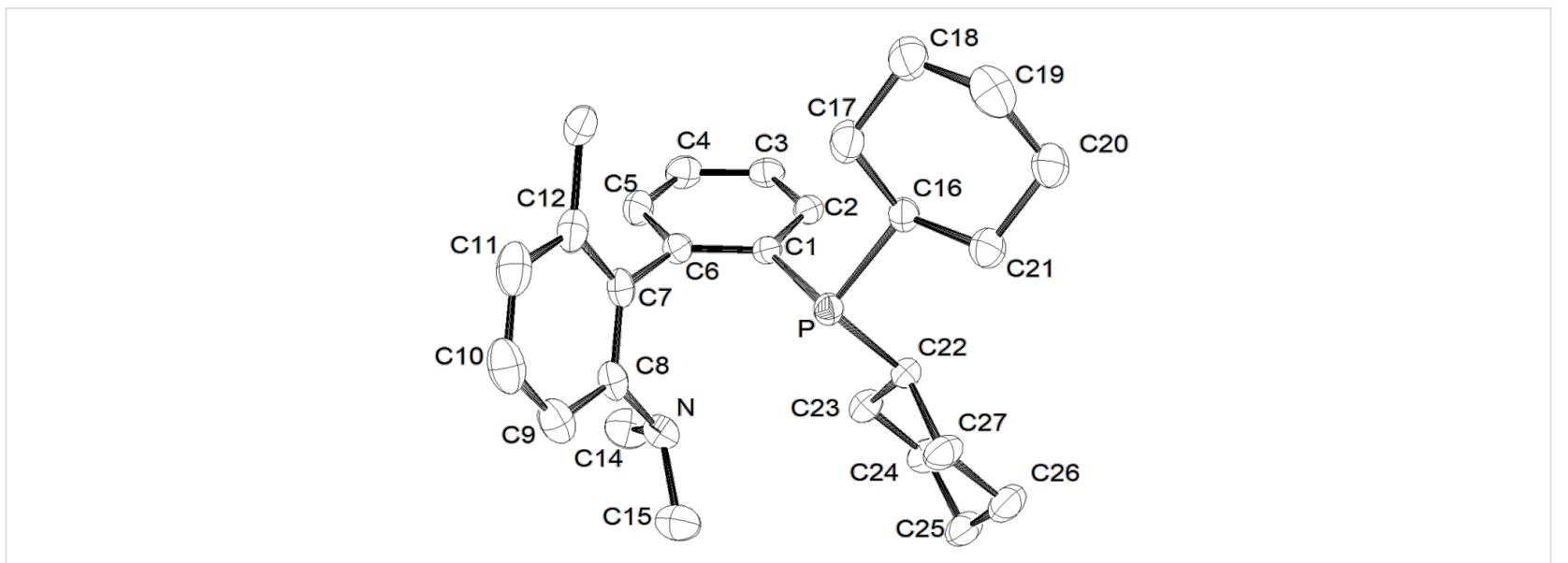

Figure 4: Molecular structure of compound 3a (crystallized from ethyl acetate/hexane) [74].

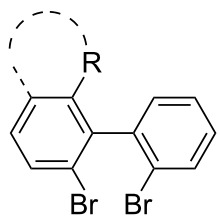

1) BuLi (1 equiv), THF, $-78^{\circ} \mathrm{C}, 1 \mathrm{~h}$

2) $\mathrm{CIPCy}_{2}$ (1 equiv), toluene, $1 \mathrm{~h}$

R $\mathrm{Cl}(\mathbf{1 g}), \mathrm{OCH}_{2} \mathrm{O}(\mathbf{1 h})$

Cy = cyclohexyl

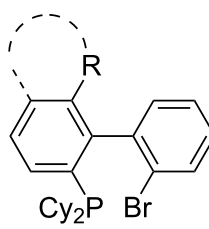

4
1) BuLi (1.1 equiv), toluene, $0{ }^{\circ} \mathrm{C}, 30 \mathrm{~min}$

2) $-78{ }^{\circ} \mathrm{C}, 1 \mathrm{~h}$

3) $\mathrm{CIPCy}_{2}$ (1.1 equiv), toluene, $1 \mathrm{~h}$

Cl (a; 73\%),

$\mathrm{NMe}_{2}(\mathbf{b} ; 63 \%)$,

OMe (c; $79 \%)$,

$\mathrm{Ph}$ (d; 75\%),

$\mathrm{OCH}_{2} \mathrm{O}(\mathbf{e} ; 55 \%)$

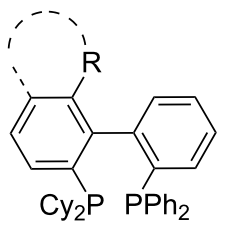

5

$\mathrm{Cl}(\mathbf{a} ; 81 \%)$,

$\mathrm{NMe}_{2}(\mathbf{b} ; 55 \%)$

OMe (c; $64 \%)$,

$\mathrm{Ph}$ (d; 85\%),

$\mathrm{OCH}_{2} \mathrm{O}(\mathbf{e} ; 66 \%)$

Scheme 4: Preparation of mixed dialkyl(diaryl)phosphinobiphenyls 5 via successive bromine-lithium exchange.

isolated and then submitted to a second bromine-lithium exchange in toluene followed by addition of $\mathrm{ClPPh}_{2}$ (Scheme 4). The lithiation-phosphination sequence was not substrate-dependent and reaction conditions were the same for all the different ortho substituents. In this way, pure ligands were obtained on a gram scale.

\section{Bis(dialkyl)phosphinobiphenyls: Path C}

In order to gain access to bis(dicyclohexylphosphino)biphenyls 3, a double bromine-lithium exchange was performed on the $2,2^{\prime}$-dibromobiaryls $\mathbf{1}$. A screening of the reaction conditions revealed higher yields for the double phosphination when the bromine-lithium exchange and trapping with $\mathrm{ClPCy}_{2}$ were carried out in toluene rather than in THF and at higher temperature. For example, with $\mathrm{R}^{1}=\mathrm{Me}, \mathrm{OCF}_{2} \mathrm{O}$, and $\mathrm{OCF}_{2} \mathrm{CF}_{2} \mathrm{O}$, the corresponding diphosphines were obtained in a yield of 54\% (in toluene) versus $12 \%$ (in THF), $53 \%$ versus $36 \%$ and $73 \%$ versus $35 \%$, respectively (Table 1, entries 1, 2, 9, 10, 11 and 12). A series of bis(dicyclohexylphosphino)biphenyls 6 was obtained in good yield. However, we noticed lower yields for biaryls carrying $\alpha$-fluorinated ether substituents, such as $\mathrm{OCF}_{2} \mathrm{O}\left(53 \%\right.$; Table 1, entry 9) or $\mathrm{OCF}_{3}$ (33\%; Table 1 , entry 14), in comparison with their nonfluorinated counterparts, $\mathrm{OCH}_{2} \mathrm{O}(70 \%$; Table 1, entry 8) and OMe [30] (74\%; Table 1, entry 5).

In the case of 2- $N, N$-dimethylamino-2',6-dibromobiphenyl (1c), higher yields were obtained when the double bromine-lithium exchange was realized successively instead of simultaneously. Indeed, the double phosphination in THF or toluene gave the corresponding ligand in a very poor yield (Table 1, entries 3 and 4). When the first $\mathrm{Br}-\mathrm{Li}$ exchange was carried out in THF at $-78{ }^{\circ} \mathrm{C}$, followed by trapping with $\mathrm{ClPCy}_{2}$, the corresponding monophosphine 7 was obtained in a good yield of $63 \%$. The second $\mathrm{Br}-\mathrm{Li}$ exchange was performed in toluene at $0{ }^{\circ} \mathrm{C}$, affording ligand $\mathbf{6 c}$ in a moderate yield of $44 \%$ after trapping with $\mathrm{ClPCy}_{2}$ (Scheme 5).

Single crystal X-ray analysis of $\mathbf{6 c}$ was performed (see Supporting Information File 6) [74]. 
Table 1: Synthesis of bis(dicyclohexylphosphino)biphenyls 6 .<smiles>[X]c1ccccc1-c1c(Br)ccc2c1CCCN2</smiles>

$\mathrm{X}=\mathrm{Br}, \mathrm{I}$

$\mathrm{X}=\mathrm{Br}$
1) RLi ( $n$ equiv), solvent, $\boldsymbol{T}, \boldsymbol{t}$

2) $\mathrm{CIPCy}_{2}$ ( $n$ equiv), toluene, $T^{\prime}, t^{\prime}$

$1,-\cdots$

' $\quad \mathrm{R}=\mathrm{Me}(\mathbf{b}), \mathrm{NMe}_{2}(\mathbf{c}), \mathrm{OMe}(\mathbf{d}), \mathrm{Ph}(\mathbf{f})$

$\mathrm{Cl}(\mathbf{g}), \mathrm{OCH}_{2} \mathrm{O}(\mathbf{h}), \mathrm{OCF}_{2} \mathrm{O}(\mathrm{i})$,

$\mathrm{OCF}_{2} \mathrm{CF}_{2} \mathrm{O}(\mathrm{j}), \mathrm{F}(\mathbf{k}), \mathrm{OCF}_{3}(\mathrm{I})$

$\mathrm{Cy}=$ cyclohexyl

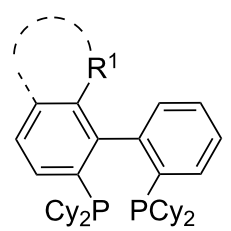

6

\begin{tabular}{|c|c|c|c|c|c|c|c|c|c|c|c|}
\hline Entry & $\mathrm{R}^{1}$ & $X$ & $\mathrm{RLi}$ & $n$ & Solvent & $T\left[{ }^{\circ} \mathrm{C}\right]$ & $t$ & $T\left[{ }^{\circ} \mathrm{C}\right]$ & $t^{\prime}$ & Ligand & Yield \\
\hline 1 & $\mathrm{Me}$ & $\mathrm{Br}$ & BuLi & 2 & toluene & 110 & $1 \mathrm{~h}$ & 50 & $2 \mathrm{~h}$ & $6 b$ & $54 \%$ \\
\hline 2 & $\mathrm{Me}$ & $\mathrm{Br}$ & BuLi & 2 & THF & -78 & $1 \mathrm{~h}$ & -78 & $1 \mathrm{~h}$ & $6 b$ & $12 \%$ \\
\hline 3 & $\mathrm{NMe}_{2}$ & $\mathrm{Br}$ & $t$-BuLi & 4 & THF & -78 & $1 \mathrm{~h}$ & -78 & $1 \mathrm{~h}$ & $6 c$ & $22 \%$ \\
\hline 4 & $\mathrm{NMe}_{2}$ & $\mathrm{Br}$ & BuLi & 2 & toluene & 0 & $15 \mathrm{~min}$ & -78 & $1 \mathrm{~h}$ & $6 c$ & $30 \%$ \\
\hline 5 & OMe [30] & $\mathrm{Br}$ & BuLi & 2 & THF & -78 & $1 \mathrm{~h}$ & -78 & $1 \mathrm{~h}$ & $6 d$ & $74 \%$ \\
\hline 6 & $\mathrm{Ph}$ & $\mathrm{Br}$ & $t$-BuLi & 4 & THF & -78 & $1 \mathrm{~h}$ & -78 & $1 \mathrm{~h}$ & $6 f$ & $66 \%$ \\
\hline 7 & $\mathrm{Cl}$ & $\mathrm{Br}$ & BuLi & 2 & THF & -78 & $1 \mathrm{~h}$ & -78 & $1 \mathrm{~h}$ & $6 \mathrm{~g}$ & $49 \%$ \\
\hline 8 & $\mathrm{OCH}_{2} \mathrm{O}$ & $\mathrm{Br}$ & BuLi & 2 & toluene & 110 & $1 \mathrm{~h}$ & 50 & $2 \mathrm{~h}$ & $6 h$ & $70 \%$ \\
\hline 9 & $\mathrm{OCF}_{2} \mathrm{O}$ & I & BuLi & 3 & toluene & 25 & $1 \mathrm{~h}$ & 25 & $2 \mathrm{~h}$ & $6 i$ & $53 \%$ \\
\hline 10 & $\mathrm{OCF}_{2} \mathrm{O}$ & I & BuLi & 3 & THF & -78 & $1 \mathrm{~h}$ & -78 & $1 \mathrm{~h}$ & $6 i$ & $36 \%$ \\
\hline 11 & $\mathrm{O}\left(\mathrm{CF}_{2}\right)_{2} \mathrm{O}$ & I & BuLi & 3 & toluene & 25 & $1 \mathrm{~h}$ & 25 & $2 \mathrm{~h}$ & 6j & $73 \%$ \\
\hline 12 & $\mathrm{O}\left(\mathrm{CF}_{2}\right)_{2} \mathrm{O}$ & I & BuLi & 3 & THF & -78 & $1 \mathrm{~h}$ & -78 & $1 \mathrm{~h}$ & $6 \mathbf{j}$ & $35 \%$ \\
\hline 13 & $\mathrm{~F}$ & $\mathrm{Br}$ & BuLi & 2 & THF & -78 & $15 \min$ & -78 & $1 \mathrm{~h}$ & $6 k$ & $79 \%$ \\
\hline 14 & $\mathrm{OCF}_{3}$ & $\mathrm{Br}$ & BuLi & 2 & toluene & 110 & $1 \mathrm{~h}$ & 50 & $2 \mathrm{~h}$ & $6 I$ & $33 \%$ \\
\hline
\end{tabular}

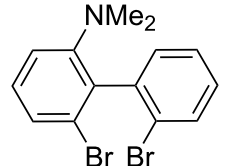

$1 \mathrm{c}$

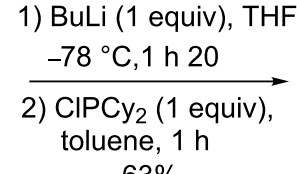

$63 \%$

Cy = cyclohexy

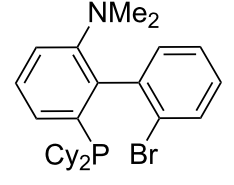

7
1) BuLi (1.1 equiv), toluene,

$0{ }^{\circ} \mathrm{C}, 15 \mathrm{~min}$

2) $-78^{\circ} \mathrm{C}, 1 \mathrm{~h}$

3) $\mathrm{CIPCy}_{2}$ (1.1 equiv), toluene, $1 \mathrm{~h}$

$44 \%$

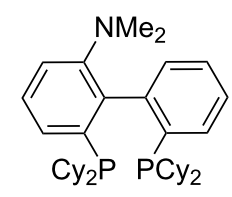

6c

Scheme 5: Stepwise bromine-lithium exchange on 1c.

\section{Phosphafluorenes and}

\section{bis(diarylphosphino)biphenyls: Path $\mathrm{D}$ and $\mathrm{E}$}

When the ortho,ortho'-dibromobiphenyls 1 were submitted to a double bromine-lithium exchange in THF followed by trapping with two equivalents of $\mathrm{ClPPh}_{2}$, whatever the nature of the ortho substituent $\left(\mathrm{R}=\mathrm{Me}, \mathrm{OMe}, \mathrm{NMe}_{2}, \mathrm{Cl}, \mathrm{OCF}_{3}, \mathrm{Ph}, \mathrm{OCH}_{2} \mathrm{O}\right.$, $\mathrm{OCF}_{2} \mathrm{O}, \mathrm{OCF}_{2} \mathrm{CF}_{2} \mathrm{O}, \mathrm{H}, \mathrm{F}$ ), the formation of an intramolecular cyclization product, a dibenzophosphole, was exclusively observed. This is consistent with the observations of $\mathrm{O}$ Desponds et al. [75]. However, when THF was replaced by toluene, the outcome of the reaction could be modified in favor of the 2,2'-bis(diphenylphosphino)biphenyls 8 [27] which were still contaminated with varying amounts of phosphafluorenes 9 and triphenylphosphine (Table 2).

\section{Conclusion}

In the present work, we showed how completely regioselective bromine-lithium exchange reactions on polybrominated biphenyls allow the construction of a new family of di- and monophosphine ligands. The required polybrominated biphenyls can be easily obtained through an efficient transition metal-free aryl-aryl coupling protocol developed by our group. The regioselectivity can be explained by recent equilibration studies of M. Schlosser et al. which allowed the determination 
Table 2: Synthesis of bis(diphenylphosphino)biphenyls $\mathbf{8}$.<smiles>[X]c1ccccc1-c1c(Br)ccc2c1OCCC2</smiles>

1) BuLi ( $n$ equiv), toluene, $T$ 2) $\mathrm{ClPPh}_{2}$ ( $n$ equiv), toluene, $T^{\prime}$<smiles>[R]c1c(C)ccc(P)c1-c1ccccc1P</smiles>
8

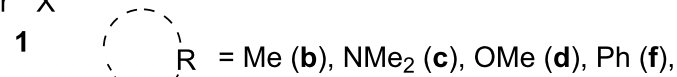<smiles>[R]c1c(C)ccc2c1c1c(n2-c2ccccc2)=C[C+]=CC=1</smiles>
$\mathrm{Cl}(\mathbf{g}), \mathrm{OCH}_{2} \mathrm{O}(\mathbf{h}), \mathrm{OCF}_{2} \mathrm{O}(\mathbf{i})$, $\mathrm{OCF}_{2} \mathrm{CF}_{2} \mathrm{O}(\mathrm{j}), \mathrm{OCF}_{3}(\mathrm{l})$

\begin{tabular}{|c|c|c|c|c|c|c|}
\hline Cpd. & $\mathrm{R}$ & $X^{\prime}$ & $n$ [equiv] & $T^{\mathrm{a}}\left[{ }^{\circ} \mathrm{C}\right]$ & $T^{\mathrm{b}}\left[{ }^{\circ} \mathrm{C}\right]$ & Yield $\mathbf{8}^{c}$ \\
\hline $8 b$ & $\mathrm{Me}$ & $\mathrm{Br}$ & 2 & 110 & 50 & $30 \%$ \\
\hline $8 c$ & $\mathrm{NMe}_{2}$ & $\mathrm{Br}$ & 2 & 110 & 50 & $44 \%$ \\
\hline $8 d$ & OMe & $\mathrm{Br}$ & 2 & 110 & 50 & $17 \%$ \\
\hline $8 f$ & $\mathrm{Ph}$ & $\mathrm{Br}$ & 2 & 110 & 50 & $24 \%$ \\
\hline $8 g$ & $\mathrm{Cl}$ & $\mathrm{Br}$ & 2 & 110 & 50 & $23 \%$ \\
\hline $8 h$ & $\mathrm{OCH}_{2} \mathrm{O}$ & $\mathrm{Br}$ & 2 & 110 & 50 & $18 \%$ \\
\hline $8 \mathbf{i}$ & $\mathrm{OCF}_{2} \mathrm{O}$ & I & 3 & 25 & 25 & $47 \%$ \\
\hline $8 \mathbf{j}$ & $\mathrm{OCF}_{2} \mathrm{CF}_{2} \mathrm{O}$ & I & 3 & 25 & 25 & $34 \%$ \\
\hline 81 & $\mathrm{OCF}_{3}$ & $\mathrm{Br}$ & 2 & 110 & 50 & $10 \%$ \\
\hline
\end{tabular}

${ }^{\mathrm{a}}$ Temperature for the halogen/metal exchange; ${ }^{\mathrm{b}}$ Trapping temperature; ${ }^{\mathrm{C}}$ Isolated yield of 8 after flash-chromatography on silica gel.

of $\Delta \Delta G$ increments for substituents at the ortho, meta, and para positions.

Overall, the methodology presented in this study offers the possibility to consider new pathways for the synthesis of more sophisticated biaryl scaffolds. Catalytic studies as well as the control of biaryl axial chirality are currently underway and will be reported in due course.

\section{Supporting Information}

\section{Supporting Information File 1}

Experimental details and spectroscopic data for new compounds.

[http://www.beilstein-journals.org/bjoc/content/ supplementary/1860-5397-7-148-S1.pdf]

\section{Supporting Information File 2}

Crystal structure data for $\mathbf{3 a}$.

[http://www.beilstein-journals.org/bjoc/content/ supplementary/1860-5397-7-148-S2.pdf]

\section{Supporting Information File 3}

Crystal structure data for $\mathbf{3 b}$.

[http://www.beilstein-journals.org/bjoc/content/ supplementary/1860-5397-7-148-S3.pdf]

\section{Supporting Information File 4}

Crystal structure data for $\mathbf{3 d}$.

[http://www.beilstein-journals.org/bjoc/content/ supplementary/1860-5397-7-148-S4.pdf]

\section{Supporting Information File 5}

Crystal structure data for $\mathbf{3 f}$.

[http://www.beilstein-journals.org/bjoc/content/ supplementary/1860-5397-7-148-S5.pdf]

\section{Supporting Information File 6}

Crystal structure data for $\mathbf{6 c}$.

[http://www.beilstein-journals.org/bjoc/content/ supplementary/1860-5397-7-148-S6.pdf]

\section{Acknowledgements}

We thank the CNRS and the Ministère de la Recherche of France. We are very grateful to LONZA AG, Switzerland for a $\mathrm{PhD}$ grant for L.B. We also thank Dr. Lydia Brelot, Université de Strasbourg, for single crystal X-ray analysis.

\section{References}

1. Patchett, A. A.; Nargund, R. P. Annu. Rep. Med. Chem. 2000, 35, 289-298. doi:10.1016/S0065-7743(00)35027-8 
2. Bringmann, G.; Breuning, M.; Tasler, S. Synthesis 1999, 525-558. doi:10.1055/s-1999-3435

3. Miyashita, A.; Yasuda, A.; Takaya, H.; Toriumi, K.; Ito, T.; Souchi, T.; Noyori, R. J. Am. Chem. Soc. 1980, 102, 7932-7934. doi:10.1021/ja00547a020

4. Zhang, X.; Mashima, K.; Koyano, K.; Sayo, N.; Kumobayashi, H.; Akutagawa, S.; Takaya, H. Tetrahedron Lett. 1991, 32, 7283-7286. doi:10.1016/0040-4039(91)80499-V

5. Schmid, R.; Cereghetti, M.; Heiser, B.; Schönholzer, P.; Hansen, H.-J. Helv. Chim. Acta 1988, 71, 897-929. doi:10.1002/hlca.19880710427

6. Schmid, R.; Foricher, J.; Cereghetti, M.; Schönholzer, P. Helv. Chim. Acta 1991, 74, 370-389. doi:10.1002/hlca.19910740215

7. Saito, T.; Yokozawa, T.; Zhang, X.; Sayo, N. Chiral diphosphine compound, intermediate for preparing the same transition metal complex having the same diphosphine compound as ligand and asymmetric hydrogenation catalyst. Eur. Pat. EP 0850945 A1, July 1 , 1998.

8. Sayo, N.; Saito, T.; Yokozawa, T. Ruthenium-phosphine complex and method for producing the same. Eur. Pat. EP 0945457 A2, Sept 29, 1999.

9. Saito, T.; Yokozawa, T.; Ishizaki, T.; Moroi, T.; Sayo, N.; Miura, T.; Kumobayashi, H. Adv. Synth. Catal. 2001, 343, 264-267. doi:10.1002/1615-4169(20010330)343:3<264::AID-ADSC264>3.0.CO; 2-T

10. Pai, C.-C.; Lin, C.-W.; Lin, C.-C.; Chen, C.-C.; Chan, A. S. C.; Wong, W. T. J. Am. Chem. Soc. 2000, 122, 11513-11514. doi:10.1021/ja000163n

11. Pai, C.-C.; Li, Y.-M.; Zhou, Z.-Y.; Chan, A. S. C. Tetrahedron Lett. 2002, 43, 2789-2792. doi:10.1016/S0040-4039(02)00383-0

12. Duprat de Paule, S.; Jeulin, S.; Ratovelomanana-Vidal, V.; Genêt, J.-P.; Champion, N.; Dellis, P. Tetrahedron Lett. 2003, 44, 823-826. doi:10.1016/S0040-4039(02)02637-0

13. Zhang, Z.; Qian, H.; Longmire, J.; Zhang, X. J. Org. Chem. 2000, 65, 6223-6226. doi:10.1021/jo000462v

14. Jeulin, S.; Duprat de Paule, S.; Ratovelomanana-Vidal, V.; Genêt, J.-P.; Champion, N.; Dellis, P. Angew. Chem., Int. Ed. 2004, 43, 320-325. doi:10.1002/anie.200352453

15. Leroux, F.; Gorecka, J.; Schlosser, M. Synthesis 2004, 326-328. doi:10.1055/s-2004-815926

16. Mettler, H.; Leroux, F. Process for the preparation of $(S)$ - or (R)-4-halo-3-hydroxybutyrates. WO Pat. Appl. WO 2005049545 A1, June 2, 2005

17. Trost, B. M.; Verhoeven, T. R. 57 - Organopalladium Compounds in Organic Synthesis and in Catalysis. In Comprehensive Organometallic Chemistry; Wilkinson, G.; Stone, F. G. A.; Abel, E. W., Eds.; Pergamon: Oxford, UK, 1982; Vol. 8, pp 799-938. doi:10.1016/B978-008046518-0.00121-5

18. Tsuji, J. Palladium Reagents and Catalysts; John Wiley and Sons: Chichester, UK, 1995.

19. Farina, V. 3.4 - Transition Metal Alkyl Complexes: Oxidative Addition and Transmetallation. In Transition Metal Organometallics in Organic Synthesis; Abel, E.; Stone, F. G. A.; Wilkinson, G., Eds.; Comprehensive Organometallic Chemistry II, Vol. 12; Pergamon: Oxford, UK, 1995; pp 161-240.

20. Diederich, F.; Stang, P. J. Metal-catalyzed Cross-coupling Reactions; Wiley-VCH: Weinheim, Germany, 1998. doi:10.1002/9783527612222

21. Suzuki, A. J. Organomet. Chem. 1999, 576, 147-168. doi:10.1016/S0022-328X(98)01055-9

22. Miyaura, N.; Suzuki, A. Chem. Rev. 1995, 95, 2457-2483. doi:10.1021/cr00039a007
23. Diemer, V.; Leroux, F. R.; Colobert, F. Eur. J. Org. Chem. 2011, 327-340. doi:10.1002/ejoc.201001217

24. Diemer, V.; Garcia, J. S.; Leroux, F. R.; Colobert, F. J. Fluorine Chem. 2011, in press. doi:10.1016/j.jfluchem.2011.02.017

25. Diemer, V.; Begaud, M.; Leroux, F. R.; Colobert, F. Eur. J. Org. Chem. 2011, 341-354. doi:10.1002/ejoc.201001283

26. Bonnafoux, L.; Gramage-Doria, R.; Colobert, F.; Leroux, F. R. Chem.-Eur. J. 2011, in press. doi:10.1002/chem.201101529

27. Bonnafoux, L.; Ernst, L.; Leroux, F. R.; Colobert, F. Eur. J. Inorg. Chem. 2011, 3387-3397. doi:10.1002/ejic.201100428

28. Bonnafoux, L.; Colobert, F.; Leroux, F. R. Synlett 2010, 2953-2955. doi:10.1055/s-0030-1259025

29. Colobert, F.; Valdivia, V.; Choppin, S.; Leroux, F. R.; Fernandez, I.; Alvarez, E.; Khiar, N. Org. Lett. 2009, 11, 5130-5133. doi:10.1021/ol9020755

30. Leroux, F. R.; Mettler, H. Adv. Synth. Catal. 2007, 349, 323-336. doi:10.1002/adsc. 200600300

31. Leroux, F. R.; Bonnafoux, L.; Heiss, C.; Colobert, F.; Lanfranchi, D. A. Adv. Synth. Catal. 2007, 349, 2705-2713. doi:10.1002/adsc.200700211

32. Leroux, F. R.; Simon, R.; Nicod, N. Lett. Org. Chem. 2006, 3, 948-954. doi:10.2174/157017806779467979

33. Schlosser, M. Angew. Chem., Int. Ed. 2005, 44, 376-393. doi:10.1002/anie.200300645

34. Schlosser, M. Organoalkali Chemistry. In Organometallic in Synthesis: A Manual, 2nd ed.; Schlosser, M., Ed.; John Wiley and Sons: Chichester, UK, 2002; pp 1-352.

35. Leroux, F.; Schlosser, M.; Zohar, E.; Marek, I. The preparation of organolithium reagents and intermediates. In The Chemistry of Organolithium Compounds; Rappoport, Z.; Marek, I., Eds.; Wiley: Chichester, UK, 2004; Vol. 1, pp 435-493.

36. Leroux, F.; Schlosser, M. Angew. Chem., Int. Ed. 2002, 41, 4272-4274. doi:10.1002/1521-3773(20021115)41:22<4272::AID-ANIE4272>3.0.CO ;2-B

37. Bonnafoux, L. Modular Synthesis of New C1-Biaryl Ligands and Application in Catalytic Hydrogenation and Coupling Reactions. Ph.D. Thesis, Université Louis Pasteur, Strasbourg, France, 2008.

38. Leroux, F. R.; Bonnafoux, F.; Colobert, F. Process for the synthesis of 2,2',6-tribromobiphenyl. WO Pat. Appl. WO 2008/037440 A1, April 3, 2008.

39. Clayden, J. Organolithiums: Selectivity for Synthesis; Pergamon: Amsterdam, The Netherlands, 2002.

40. Marvel, C. S.; Hager, F. D.; Coffman, D. D. J. Am. Chem. Soc. 1927, 49, 2323-2328. doi:10.1021/ja01408a030

41. Wittig, G.; Pockels, U.; Droge, H. Ber. Dtsch. Chem. Ges. 1938, 71B, 1903-1912.

42. Gilman, H.; Langham, W.; Jacoby, A. L. J. Am. Chem. Soc. 1939, 61, 106-109. doi:10.1021/ja01870a036

43. Gilman, H.; Moore, F. W. J. Am. Chem. Soc. 1940, 62, 1843-1846 doi:10.1021/ja01864a058

44. Langham, W.; Brewster, R. Q.; Gilman, H. J. Am. Chem. Soc. 1941, 63, 545-549. doi:10.1021/ja01847a053

45. Jones, R. G.; Gilman, H. Chem. Rev. 1954, 54, 853-890. doi:10.1021/cr60171a004

46. Bailey, W. F.; Patricia, J. J. J. Organomet. Chem. 1988, 352, 1-46. doi:10.1016/0022-328X(88)83017-1

47. Beak, P.; Musick, T. J.; Chen, C. W. J. Am. Chem. Soc. 1988, 110, 3538-3542. doi:10.1021/ja00219a031 
48. Beak, P.; Allen, D. J. J. Am. Chem. Soc. 1992, 114, 3420-3425. doi:10.1021/ja00035a039

49. Eisch, J. J. Organometallics 2002, 21, 5439-5463. doi:10.1021/om0109408

50. Nájera, C.; Sansano, J. M.; Yus, M. Tetrahedron 2003, 59, 9255-9303. doi:10.1016/j.tet.2003.09.065

51. Leroux, F.; Nicod, N.; Bonnafoux, L.; Quissac, B.; Colobert, F. Lett. Org. Chem. 2006, 3, 165-169.

52. Leroux, F.; Mettler, H. Synlett 2006, 766-770. doi:10.1055/s-2006-933107

53. Shi, L.; Chu, Y.; Knochel, P.; Mayr, H. Org. Lett. 2009, 11, 3502-3505. doi:10.1021/ol9013393

54. Shi, L.; Chu, Y.; Knochel, P.; Mayr, H. J. Org. Chem. 2009, 74, 2760-2764. doi:10.1021/j0802770h

55. Shi, L.; Chu, Y.; Knochel, P.; Mayr, H. Angew. Chem., Int. Ed. 2008, 47, 202-204. doi:10.1002/anie.200704100

56. Krasovskiy, A.; Straub, B. F.; Knochel, P. Angew. Chem., Int. Ed. 2006, 45, 159-162. doi:10.1002/anie.200502220

57. Krasovskiy, A.; Knochel, P. Angew. Chem., Int. Ed. 2004, 43, 3333-3336. doi:10.1002/anie.200454084

58. Knochel, P.; Dohle, W.; Gommermann, N.; Kneisel, F. F.; Kopp, F.; Korn, T.; Sapountzis, I.; Vu, V. A. Angew. Chem., Int. Ed. 2003, 42, 4302-4320. doi:10.1002/anie.200300579

59. Knochel, P.; Krasovskiy, A.; Sapountzis, I. Polyfunctional Magnesium Organometallics for Organic Synthesis. In Handbook of Functionalized Organometallics; Knochel, P., Ed.; Wiley-VCH: Weinheim, Germany, 2005; pp 109-172. doi:10.1002/9783527619467

60. Boudier, A.; Bromm, L. O.; Lotz, M.; Knochel, P. Angew. Chem., Int. Ed. 2000, 39, 4414-4435. doi:10.1002/1521-3773(20001215)39:24<4414::AID-ANIE4414>3.0.CO ;2-C

61. Abarbri, M.; Dehmel, F.; Knochel, P. Tetrahedron Lett. 1999, 40, 7449-7453. doi:10.1016/S0040-4039(99)01404-5

62. lida, T.; Wada, T.; Tomimoto, K.; Mase, T. Tetrahedron Lett. 2001, 42, 4841-4844. doi:10.1016/S0040-4039(01)00861-9

63. Kondo, J.; Inoue, A.; Shinokubo, H.; Oshima, K. Angew. Chem., Int. Ed. 2001, 40, 2085-2087. doi:10.1002/1521-3773(20010601)40:11<2085::AID-ANIE2085>3.0.CO ;2-K

64. Gallou, F.; Haenggi, R.; Hirt, H.; Marterer, W.; Schaefer, F.; Seeger-Weibel, M. Tetrahedron Lett. 2008, 49, 5024-5027. doi:10.1016/j.tetlet.2008.06.046

65. Choe, J.; Seo, J. H.; Kwon, Y.; Song, K. H. Chem. Eng. J. 2008, 135, S17-S20. doi:10.1016/j.cej.2007.07.015

66. Kato, S.; Nonoyama, N.; Tomimoto, K.; Mase, T. Tetrahedron Lett. 2002, 43, 7315-7317. doi:10.1016/S0040-4039(02)01747-1

67. Perron, Q.; Praz, J.; Alexakis, A. Tetrahedron: Asymmetry 2009, 20, 1004-1007. doi:10.1016/j.tetasy.2009.02.027

68. Fan, C.-A.; Ferber, B.; Kagan, H. B.; Lafon, O.; Lesot, P. Tetrahedron: Asymmetry 2008, 19, 2666-2677. doi:10.1016/j.tetasy.2008.12.003

69. Perron, Q.; Alexakis, A. Adv. Synth. Catal. 2010, 352, 2611-2620. doi:10.1002/adsc.201000517

70. Mettler, H.; Leroux, F.; Schlosser, M. Process for the preparation of asymmetrically substituted biaryldiphosphines. WO Pat. Appl. WO 2006002729 A1, Jan 12, 2006.

71. Mettler, H.; Leroux, F.; Schlosser, M. Process for the preparation of asymmetrically substituted biaryldiphosphines. WO Pat. Appl. WO 2006002731 A1, Jan 12, 2006.
72. Mettler, H.; Leroux, F.; Schlosser, M. Process for the preparation of asymmetrically substituted biaryldiphosphines. WO Pat. Appl. WO 2006002730 A1, Jan 12, 2006.

73. Gorecka-Kobylinska, J.; Schlosser, M. J. Org. Chem. 2009, 74, 222-229. doi:10.1021/jo8020083

74. CCDC 827188 (3a), CCDC 827186 (3b), CCDC 827187 (3d), CCDC 827189 (3f) and CCDC 827190 (6c) contain the supplementary crystallographic data for this paper. These data can be obtained free of charge from The Cambridge Crystallographic Data Centre via http://www.ccdc.cam.ac.uk/data_request/cif.

75. Desponds, O.; Schlosser, M. J. Organomet. Chem. 1996, 507, 257-261. doi:10.1016/0022-328X(95)05767-J

\section{License and Terms}

This is an Open Access article under the terms of the Creative Commons Attribution License

(http://creativecommons.org/licenses/by/2.0), which permits unrestricted use, distribution, and reproduction in any medium, provided the original work is properly cited.

The license is subject to the Beilstein Journal of Organic Chemistry terms and conditions: (http://www.beilstein-journals.org/bjoc)

The definitive version of this article is the electronic one which can be found at: doi:10.3762/bjoc. 7.148 